sciforum

\title{
Models to Predict pH-dependent Aqueous Solubility of Chemically Diverse Druglike Compounds
}

\author{
Gretter León Sánchez ${ }^{a}$, Laura Machín Galarza (laura@ifal.uh.cu) ${ }^{a}$, \\ Juan Carlos Polo Vega ${ }^{a}$, Luis Alberto Torres Gómez ${ }^{a}$
}

${ }^{a}$ Department of Pharmacy, Institute of Pharmacy and Food Sciences, University of Havana, Cuba.

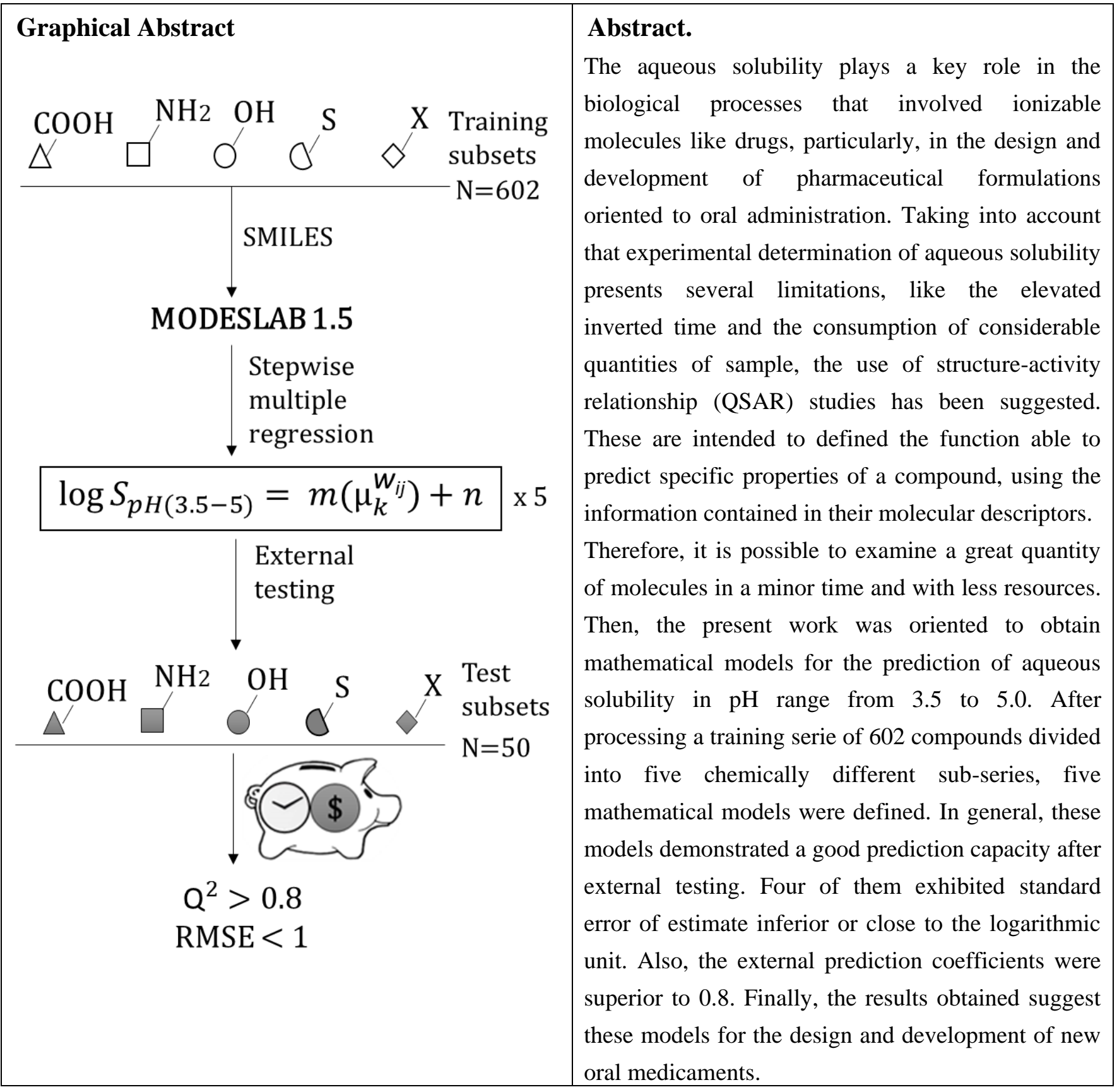


http://sciforum.net/conference/mol2net-05

\section{Introduction}

The aqueous solubility (S) plays a key role in the biological processes where drugs are involved, due to dissolution rate and permeability of molecules depend on this physicochemical parameter. ${ }^{1}$ In particular, the therapeutic efficacy of oral medications depends on drug bioavailability, which considers the extent and rate of drug absorption from the pharmaceutical preparation to the action site. ${ }^{2}$ Then, knowing the aqueous drug solubility is of major interest. In the other hand, the facility or difficulty of drugs to become ionized should be consider during experimental determination of S. ${ }^{3}$ In this sense, the final $\mathrm{pH}$ and the $\mathrm{pKa}$ of molecules are very importance, ${ }^{4}$ however they are frequently ignored.

When manipulation of reagents involved some risk and determination of a property/activity results complex, an interesting alternative are quantitative structure property relationship (QSPR) studies. These methodologies are oriented to find the best functions that predict a compound specific property through its molecular descriptors. Also, QSPR studies analyze a great quantity of molecules in less time and with minus resources. Therefore, they can be recommended to accelerated the development of pharmaceutical products. ${ }^{5}$

The quality of mathematical models depends on several factors like the descriptors, whose determination can be based on different theories. ${ }^{6}$ In this sense, the TOPS-MODE approach can be used in order to calculated the spectral moments of the adjacency matrix between edges of the molecular graph with suppressed hydrogens ${ }^{7-11}$. Therefore, the aims of this work were to generate and evaluate mathematical functions oriented to predict the aqueous solubility of ionizable molecules considering their chemical behavior and $\mathrm{pH}$ range close to acidity.

\section{Materials and Methods}

Training set and solubility source. According to a qualitative classification criterion that consider the chemical functional groups and the IUPAC priority, the training set was divided in five groups: (1) acids, (2) bases, (3) neutrals, (4) sulphured and (5) hydrocarbons of 126, 131, 123, 89 and 133 molecules, respectively. The sets were assembled from ACD/Labs version $10.04,{ }^{12}$ commercial software employed to obtain the $\mathrm{S}$ values (in logarithmic scale) of compounds in $\mathrm{pH}$ interval from 3.5 to 5 .

Descriptors. The SMILES derived from ACD/Labs were introduced in the software package MODESLAB version $1.5,{ }^{13}$ which includes the TOPS-MODE approach used to generate the molecular descriptors. The mathematical details of the method have been largely reported ${ }^{14-16}$. As a result, a matrix containing the spectral moments from $\mu_{1}$ to $\mu_{15}$ was obtained per weight, in addition to the $\mu_{0}$ (number of atoms), leading to a total of 91 molecular descriptors for each compound. The selection of these parameters to weight the matrix was based on the influence of them in solubility behavior of ionizable molecules. Therefore, the descriptors calculated allowed the adequate codification of the molecular structure.

Statistical tools. Group-specific QSPR models were developed considering the whole pool of calculated descriptors. The statistical processing was carried out by using the stepwise multiple regression, where the independent variables are individually deleted from the model in order to obtain the best one. 
pH-dependent aqueous solubility prediction of a test set. Following the same classification criterion, a test set of 50 compounds was divided in five chemically different groups of ten molecules each. These sub-series were used to evaluate the prediction power of QSPR models outside the training set.

Validation of models. The determination coefficient $\left(\mathrm{R}^{2}\right)$, the prediction coefficient for external test $\left(\mathrm{Q}^{2}\right)$ and the external root mean square error (RMSE $\left.\mathrm{ext}\right)$ determined the accuracy of the models.

\section{Results and Discussion}

After processing the training sub-sets (acids, bases, neutrals, sulphured and hydrocarbons + halogens) five mathematical predictive models (1-5) were obtained (See Table 1). The inclusion of less than ten predictive variables (five, seven, four, five and five, respectively) in each model highlights the economy of descriptors achieved, which is desirable for a better interpretation of results.

Table 1. Models to predict pH-dependent aqueous solubility

\begin{tabular}{|c|c|c|}
\hline$\#$ & Equations & Sub-serie \\
\hline 1 & $\begin{aligned} \log S_{p H: 3.5-5}=- & 0,1379\left(\mu_{3}^{\text {dip }}\right)+0,0382\left(\mu_{4}^{\text {dip }}\right)-0,0021\left(\mu_{5}^{\text {hyd }}\right)-0,1342\left(\mu_{2}^{\text {pol }}\right) \\
& +0,0319\left(\mu_{1}^{\text {ato }}\right)+0,5412\end{aligned}$ & acids \\
\hline 2 & $\begin{aligned} \log S_{p H: 3.5-5}=- & 2,8777\left(\mu_{0}\right)-0,1278\left(\mu_{3}^{\text {pol }}\right)+1,7464\left(\mu_{1}^{\text {pol }}\right)+1,3816\left(\mu_{1}^{\text {std }}\right) \\
& +0,2227\left(\mu_{3}^{\text {hyd }}\right)+0,0000\left(\mu_{5}^{\text {ato }}\right)-1,7845\left(\mu_{1}^{\text {hyd }}\right)+1,3329\end{aligned}$ & bases \\
\hline 3 & $\log S_{p H: 3.5-5}=-0,0164\left(\mu_{1}^{\text {ato }}\right)-0,4123\left(\mu_{1}^{\text {hyd }}\right)+0,0000\left(\mu_{6}^{\text {ato }}\right)+0,0032\left(\mu_{3}^{\text {dip }}\right)+1,0371$ & neutrals \\
\hline 4 & $\begin{aligned} \log S_{p H: 3.5-5}=- & 0,6955\left(\mu_{2}^{\text {pol }}\right)+0,1299\left(\mu_{3}^{\text {pol }}\right)+1,6418\left(\mu_{0}\right)-0,3889\left(\mu_{1}^{\text {van }}\right) \\
& -0,0000\left(\mu_{5}^{\text {ato }}\right)+0,8201\end{aligned}$ & sulphured \\
\hline 5 & $\begin{array}{c}\log S_{p H: 3.5-5}=-1,3805\left(\mu_{1}^{\text {std }}\right)+1,6610\left(\mu_{0}\right)+0,1359\left(\mu_{2}^{\text {pol }}\right)-0,4642\left(\mu_{1}^{\text {pol }}\right) \\
-0,0000\left(\mu_{6}^{\text {ato }}\right)-0,5212\end{array}$ & $\begin{array}{l}\text { hydrocarbons } \\
+ \text { halogens }\end{array}$ \\
\hline
\end{tabular}

The statistical parameters obtained for the five QSPR models after external validation are shown in table 2 .

Table 2. Performance on the test set of the QSPR models.

\begin{tabular}{|l|c|c|c|c|}
\hline Group & eq & $\mathrm{Q}^{2}$ & $\mathrm{R}^{2}-\mathrm{Q}^{2}$ & RMSE ext \\
\hline Acids & 1 & 0,862 & 0,213 & 0,874 \\
\hline Bases & 2 & 0,811 & 0,094 & 0,703 \\
\hline Neutrals & 3 & 0,950 & 0,057 & 0,345 \\
\hline Sulphured & 4 & 0,805 & 0,023 & 1,035 \\
\hline $\begin{array}{l}\text { Hydrocarbons } \\
\text { + halogens }\end{array}$ & 5 & 0,984 & 0,106 & 2,321 \\
\hline
\end{tabular}

$\mathrm{R}^{2}$ : determination coefficient, $\mathrm{Q}^{2}$ : prediction coefficient for external test, $\mathrm{RMSE}$ ext: standard error for external test. 
The five models accomplished the external validation criteria, due to $\mathrm{Q}^{2}>0,8$ and $\mathrm{R}^{2}-\mathrm{Q}^{2}<0,3$. According to the $\mathrm{Q}^{2}$ obtained, we can consider that the models obtained are capable to explain around the $80 \%$ of the variability of aqueous solubility outside the training molecules. Also, the RMSEext inferior or close to the logarithmic unit obtained for models 1-4 indicates an adequate prediction capacity of them. The higher value achieved after testing the fifth model may be associated to the structural variability of the correspondent group, which includes aromatic and aliphatic compounds of saturated and/or unsaturated chemical nature.

\section{Conclusions}

Four of the mathematical predictive models defined exhibited a good predictive capacity. Therefore, the use of them is suggested in the prediction of aqueous solubility of druglike molecules in a range close to acidity.

\section{References}

1. Alelyunas, Y. W.; Empfield, J. R.; McCarthy, D.; Spreen, R. C.; Bui, K.; Pelosi-Kilby, L.; Shen, C. Experimental solubility profiling of marketed CNS drugs, exploring solubility limit of CNS discovery candidate. Bioorg. Med. Chem. Lett. 2010, 20, 7312-7316.

2. Morgan P, Van Der Graaf PH, Arrowsmith J, Feltner DE, Drummond KS y col. Can the flow of medicines be improved? Fundamental pharmacokinetic and pharmacological principles toward improving Phase II survival. Drug Discov Today. 2012, 17, 419-24.

3. Comer, J. E. A. High-throughput Measurement of $\log$ D and pKa. In Drug Bioavailability; Van de Waterbeemd, H., Lennernas, H., Artursson, P., Eds.; VCH: New York, 2003, 21-45.

4. Li, P., Tabibi, S. E., Yalkowsky, S. H. Solubilization of ionized and un-ionized flavopiridol by ethanol and polysorbate 20. J. Pharm. Sci. 1999, 88,507-509.

5. Podunavac-Kuzmanović, S. O.; Cvetković, D. D.; Barna, D. J. QSAR Analysis of 2-Amino or 2Methyl-1-Substituted Benzimidazoles Against Pseudomonas aeruginosa. Int. J. Mol. Sci. 2009, 10, 1670-1682.

6. Katritzky, A. R.; Lobanov, V. S.; Karelson, M. QSPR - the correlation and quantitative prediction of chemical and physical properties from structure. Chem. Soc. Rev. 1995, 24, $279-287$.

7. Cabrera, M. A.; Bermejo, M.; Ramos, L.; Grau, R.; Pérez, M.; González, H. A topological sub-structural approach for predicting human intestinal absorption of drugs. Eur. J. Med. Chem. 2004, 39, 905-916.

8. Pérez, M.; Morales, A.; González, H. A TOPS-MODE approach to predict permeability coefficients. Polymer, 2004, 45, 2073-2079.

9. Molina, E.; Sobarzo-Sanchez, E.; Speck-Planche, A.; Matos, M. J.; Uriarte, E.; Santana, L.; Yáñez, M.; Orallo, F. Monoamino oxidase a: an interesting pharmacological target for the development of multitarget QSAR. Mini. Rev. Med. Chem. 2012, 12, 947-958.

10. Morales, A.; Pérez, M.; Rieumont, J. TOPS-MODE approach to predict mutagenicity in dental monomers. Polymer, 2004, 45, 2045-2050.

11. Rojas-Vargas, J. A.; Speck-Planche, A.; García-López, A.; Acevedo-Martínez, J. Modelación del índice de retención en iminas usando descriptores TOPS-MODE. Rev. Cub. Quím. 2012, 24, 272-283.

12. ACD/Labs software, version 10.04; ACD/Labs 1994-2007. Available at http://www.acdlabs.com/ilab/.

13. MODESLAB software, version 1.5; Estrada, E. and Gutiérrez, Y.; 2002-2004. Available at http://www.modeslab.

14. Estrada, E. Spectral Moments of the Edge Adjacency Matrix in Molecular Graphs. 1. Definition and Applications to the Prediction of Physical Properties of Alkanes. J. Chem. Inf. Comput. Sci. 1996, 36, 844-849.

15. Estrada, E. Spectral Moments of the Edge-Adjacency Matrix of Molecular Graphs. 2. Molecules Containing Heteroatoms and QSAR Applications. J. Chem. Inf. Comput. Sci. 1997, 37, 320-328.

16. Estrada, E. Spectral Moments of the Edge Adjacency Matrix in Molecular Graphs. 3. Molecules Containing Cycles J. Chem. Inf. Comput. Sci. 1998, 38, 23-27. 